\title{
Acute Submassive Pulmonary Embolism Following Varicose Vein Surgery in a Patient Receiving Hormonal Replacement Therapy
}

\author{
Masayasu Nishibe, MD, ${ }_{1}^{1}$ Fabio Kudo, MD, ${ }^{1}$ Yuka Kondo, MD,${ }^{2}$ Akihito Muto, MD, ${ }^{2}$ Alan Dardik, MD, ${ }^{2}$ \\ Jun Koizumi, MD, ${ }^{3}$ and Toshiya Nishibe $\mathrm{MD}^{1}$
}

\begin{abstract}
Acute pulmonary embolism following varicose vein surgery is reported in a patient receiving hormonal replacement therapy. A 45-year-old woman underwent partial stripping of the greater saphenous vein of her bilateral legs and division of the lesser saphenous vein of her left legs under spinal anesthesia. On the first postoperative day, she complained of severe chest discomfort and collapsed suddenly while walking to the toilet. Emergency spiral computed tomography and perfusion scintigraphy demonstrated multiple defects in the bilateral lower lobes. She recovered after aggressive anticoagulant therapy. Although acute pulmonary embolism occurs only rarely after varicose vein surgery, it is important to remember its possibility especially when a patient has known risk factors predisposing venous thromboembolism, such as hormone replacement therapy.
\end{abstract}

Key words: varicose vein, stripping, acute pulmonary embolism, hormonal replacement therapy

\section{INTRODUCTION}

$\mathrm{T}$ The morbidity of varicose vein surgery, which is often considered minor surgery, is poorly documented in the surgical literature and is often underreported. However, although very rare, acute pulmonary embolism may follow varicose vein surgery, as it may in any other operations. This report describes acute submassive pulmonary thromboembolism following saphenous vein stripping in a patient receiving hormonal replacement therapy, and reviews the incidence and etiology of this condition.

${ }^{1}$ Department of Surgery, Eniwa Midorino Clinic, Eniwa, Hokkaido, Japan

${ }^{2}$ Department of Vascular Surgery, Yale University School of Medicine, New Haven, CT, USA

${ }^{3}$ Departement of Diagnostic Radiology, Tokai University School of Medicine, Isehara, Kanagawa, Japan

Received: December 26, 2008 Accepted: January 19, 2010. Address for reprint requests to Toshiya Nishibe, MD, PhD: Department of Surgery, Eniwa Midorino Clinic, 1-5-3 Midorimachi, Eniwa, Hokkaido 061-1442, Japan

TEL: +81-123-32-6766, FAX: +81-123-32-6711

\section{Case Report}

A 45-year-old woman developed superficial varicose veins with dullness and cramp (Class ${ }_{2, s}$ with CEAP clinical manifestation) on her bilateral legs several years ago. She experienced twice pregnancy and deliveries. She was receiving hormonal replacement therapy with conjugated estrogens ( $0.625 \mathrm{mg}$ per day) for a menopausal disorder. A physical examination of her legs revealed varicose veins in the upper calf. Ascending venography was performed as described previously. ${ }^{1}$ With the patient in the 60-degree semi-upright position, the contrast medium was injected into a foot vein with tourniquets around the thigh and ankle. Saphenofemoral incompetence on her bilateral legs as well as saphenopopliteal incompetence on her left leg was detected, but no deep venous thrombosis was observed.

Partial stripping of the greater saphenous vein (GSV) of her bilateral legs and division of the small saphenous vein (SSV) of her left legs were performed under spinal anesthesia. As described previously, ${ }^{1)}$ the GSV and its tributaries were ligated and divided at the saphenofemoral junction, and then the GSV was stripped downward 


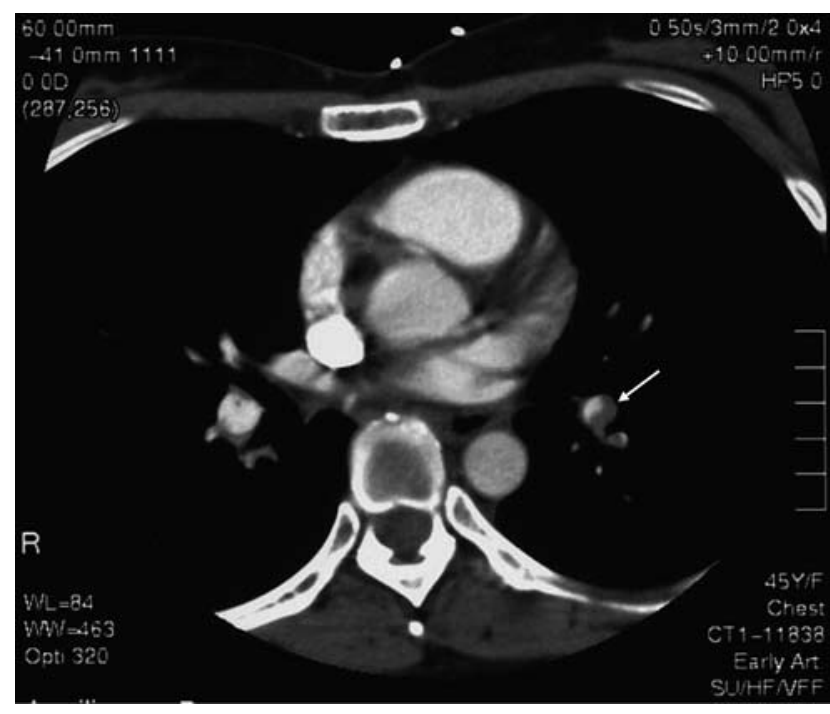

Fig. 1 Emergency spiral computed tomography demonstrating a partial intraluminal defect in the left lower lobe artery (arrow).

from the groin to the knee. The SSV was ligated and divided at the saphenopopliteal junction. Elastic bandages were used continuously. The patient came out from under the anesthesia about 3 hours after operation.

The patient was hospitalized and was stable on the day of surgery. On the first postoperative day, she complained of severe chest discomfort and suddenly collapsed while walking to the toilet. When transferred to her bed, her pulse was rhythmic at 90 beats $/ \mathrm{min}$, blood pressure was $70 \mathrm{mmHg}$, and the $\mathrm{SaO}_{2}$ was $80 \%$. An electrocardiogram and a chest radiograph were unremarkable. An arterial blood sample showed marked hypoxia and hypercapnia. Emergency spiral computed tomography demonstrated a partial intraluminal defect in the left lower lobe artery (Fig. 1). Emergency perfusion scintigraphy also revealed multiple defects in the bilateral lower lobes (Fig. 2). A diagnosis of acute submassive pulmonary thromboembolism was made, and anticoagulant therapy was started, and fortunately the patient recovered from shock very quickly. Heparin was injected continuously through an antecubital vein at the dosage of $17500 \mathrm{U} /$ day for 8 days. Thrombin-antithrombin III complex (enzyme-linked immunosorbent assay, normal range $<3.0 \mathrm{ng} / \mathrm{ml}$ ) and D-dimer (latex agglutination assay, normal range $<0.72 \mu \mathrm{g} /$ $\mathrm{ml}$ ) were later found to be elevated to $30.9 \mathrm{ng} / \mathrm{ml}$ and $11.13 \mu \mathrm{g} / \mathrm{ml}$, respectively.

Spiral computed tomography and ventilation perfusion scintigraphy performed on the 14th and 18th postopera- tive day, respectively, demonstrated complete thrombolysis in the left lung. Although postoperative duplex ultrasonography did not show a trace of deep venous thrombosis, the clinical course suggested that acute pulmonary thromboembolism might be followed by deep venous thrombosis. Coagulation factors, including antithrombin III, protein C, protein S, plasminogen, fibrinogen, antinuclear antibody, or anticardiolipin antibody did not show a defect predisposing to thrombophilia. Homocysteine serum concentration, prothrombin gene mutation, factor $\mathrm{V}$ Leiden mutation, or methylentetrahydrofolate reductase gene mutation were not examined. The patient was put under warfarin control after discharge.

\section{DiscuSSION}

Surgery is one of the recognized risk factors for deep venous thrombosis and pulmonary thromboembolism. Their incidence is especially dependent on the type of the surgical procedure. The overall incidence of deep venous thrombosis is approximately 19\% in patients undergoing general surgery, $24 \%$ for elective neurosurgical procedures, and $48 \%, 51 \%$, and $61 \%$ among those undergoing surgery for hip fracture, hip arthroplasty and knee arthroplasty, respectively. ${ }^{3)}$

Several published series involving large numbers have demonstrated the low incidences of deep venous thrombus and pulmonary embolism of varicose vein surgery. Hagmuller reported a series of 3,300 cases of varicose vein surgery in which the incidence of deep venous thrombus was $0.15 \%$ and that of pulmonary embolism was $0.06 \%$. $^{4}$ In 997 consecutive patients, Miller et al. reported the low incidence of deep venous thrombosis and pulmonary embolism of $0.4 \%$ and $0.1 \%$, respectively. Similarly, Critchley et al. reported only three deep venous thrombosis $(0.5 \%)$ and one of pulmonary embolism (0.1\%) in 973 limbs of 593 patients. $\left.{ }^{6}\right)$ We also recognized only one case of consecutive 350 patients for 5 years. The low incidence of postoperative pulmonary embolism from varicose vein surgery is attributable to several factors. Perioperative immobilization and the potential for gross venous injury, which belong in Virchow's triad, may not be present in patients undergoing varicose vein surgery. Furthermore, Miller et al. emphasized that all patients offered vein surgery are more often in otherwise good general health.

Estrogen compounds increase the risk of venous thromboembolism when used as postmenopausal replacement therapy, ${ }^{7)}$ with several studies reporting that the risk 


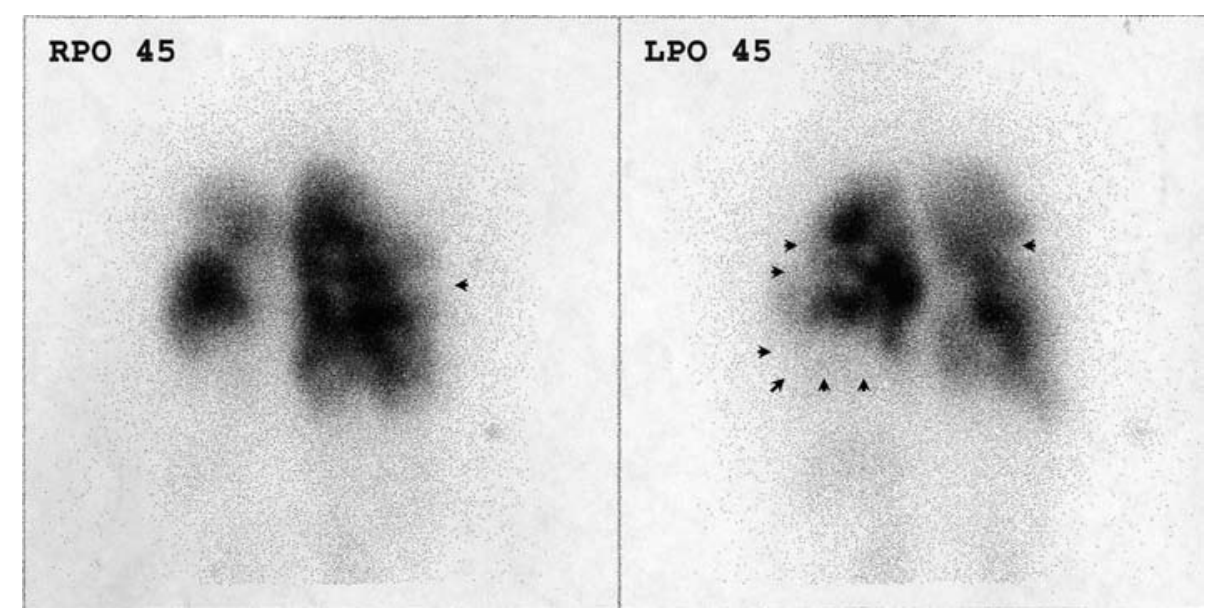

Fig. 2 Emergency perfusion scintigraphy revealing multiple defects in the bilateral lower lobes (arrowheads).

is twofold to fourfold higher among women receiving hormone replacement therapy. Estrogen is known to be associated with alterations in the coagulation system, including decreases in PAI- $1,{ }^{8}$ increases in blood viscosity, fibrinogen, plasma levels of factors VII and X, as well as platelet adhesion and aggregation. The present patient was receiving hormone replacement therapy, which may have contributed to the development of acute pulmonary thromboembolism. To minimize the risk of venous thromboembolism, taking detailed histories and appropriate blood test, including D-dimer and thrombin-antithrombin III complex, are mandatory for such patients.

Anticoagulant therapy is the mainstay in the management of venous thromboembolism. Treatment of intravenous heparin and oral anticoagulants reduces the mortality rate to less than $5 \%$, which may be lowered with the use of low-molecular-weight heparin. Thrombolytic therapy may be beneficial in patients with submassive or massive pulmonary embolism. Several studies demonstrated superiority of thrombolysis in radiographic and hemodynamic abnormalities with the first 24 hours, but this advantage was short lived.9) Fortunately the present patient recovered from shock very quickly after starting anticogulant therapy.

In conclusion, although acute pulmonary embolism occurs only rarely after varicose vein surgery, it is important to remember its possibility especially when a patient has known risk factors predisposing venous thromboembolism, such as hormone replacement therapy.

\section{REFERENCES}

1) Nishibe T, Nishibe M, Kudo F, Flores J, Miyazaki K, Yasuda K. Stripping operation with preservation of the calf saphenous veins for primary varicose veins: hemodynamic evaluation. Cardiovasc Surg. 2003; 11: 341-5.

2) Coon WW, Willis PW 3rd, Keller JB. Venous thromboembolism and other venous disease in the Tecumsch Community Health Study. Circulation. 1973; 48: 839-46.

3) Clagett GP, Anderson FA, Heit J, Pineo GF, Colwell $\mathrm{CW}$, Anderson FA, et al. Prevention of venous thromboembolism. Chest. 1995; 108 (4 suppl): 312S-34S.

4) Hagmuller GW. Complications in surgery of varicose veins. Langenbecks Arch Chir Suppl Kongressbd. 1992; 470-4.

5) Miller GV, Lewis WG, Sainsbury JRC, MacDonald RC. Morbidity of varicose vein surgery: auditing the benefit of changing clinical practice. Am R Coll Surg Engl. 1996; 78: 345-9.

6) Critchley G, Handa A, Maw A, Harvey A, Harvey MR, Corbett CR. Complications of varicose vein surgery. Ann R Coll Surg Engl. 1997; 79: 105-10.

7) Grodstein F, Stampfer MJ, Goldhaber SZ, Manson JE, Colditz GA, Speizer FE, et al. Prospective study of exogenous hormones and risk of pulmonary embolism in women. Lancet. 1996; 348: 983-7.

8) Comerota AJ. Clinical and diagnostic evaluation of deep venous thrombus. In: Rutherford RB (eds) Vascular surgery 5th edn. WB Saunders company, Philadelphia, 2003; 1937-40.

9) Arcasoy SM, Kreit JW. Thrombolytic therapy of pulmonary embolism. Chest. 1999; 155: 1695-707. 